\title{
Review of Various Power Conversion converter for battery Energy Storage Systems
}

\author{
Shankar Kumar \\ M.Tech Scholar, \\ Department of Electrical Engineering \\ Scope College of Engineering, Bhopal, India
}

\author{
Prof. N.K Singh \\ Assistant Professor \\ Department of Electrical Engineering \\ Scope College of Engineering, Bhopal, India
}

\begin{abstract}
The demand for safe and reliable electricity increases, our infrastructure continues to evolve and innovate in order to accommodate such growth. The advantages of energy storage can traverse power age, through transmission and dissemination, and right to clients. An energy storage framework is essential for pay of the active-power change; it can alleviate the unsettling influence and keep up the dependability of voltage and recurrence. Power conversion framework (PCS), as an interface between storage framework and open network, assumes an extraordinary job in accomplishing the power move between storage framework and open matrix. This paper summarize the different research dependent on power conversion converter for battery energy storage systems ebb and flow topologies and the control strategies ordinarily utilized in building under various working circumstances and prerequisites, and analyze their disparities and characters, which will helps in picking the PCS structures and control strategies.
\end{abstract}

Keywords- Power, Conversion, Converter, Energy, Battery, Storage

$* * * * *$

\section{INTRODUCTION}

Battery energy storage framework (BESS) has been utilized for certain decades in disconnected regions, particularly so as to supply energy or fulfill some administration need. There has been a transformation in power age. Today, sun oriented and wind power age, among different choices, represents a critical piece of the electric power age network all around the globe. In any case, in this situation of high degree of renewable energy, BESS assumes a key job in the efforts to join a supportable energy source with a dependable dispatched load and mitigates the effects of the irregular sources. Therefore, the establishment of BESS has expanded all through the world as of late. Regardless of their advantages, the execution of such systems faces extensive difficulties.

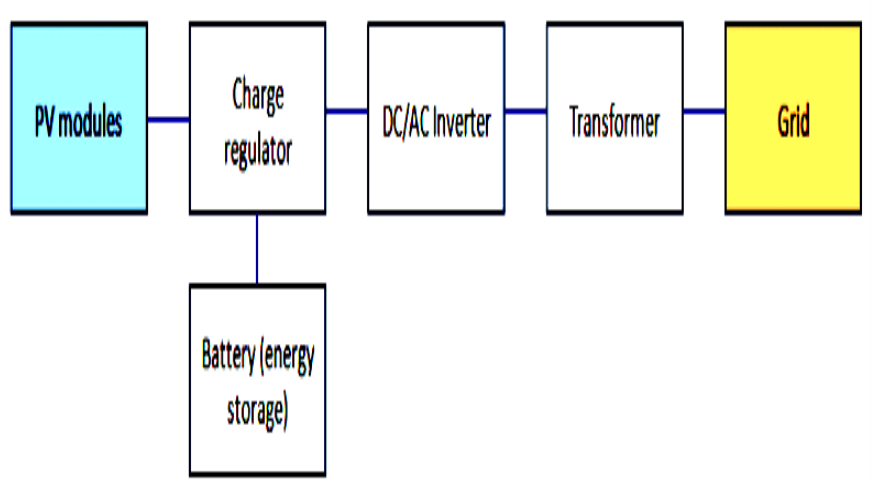

Figure 1: Block diagram of battery energy storage system
Energy storage framework comprises of two sections, storage office and PCS. PCS, the interface between storage office and small scale grid(utility framework), works the capacity of moving and swapping energy between the storage framework and the miniaturized scale lattice bidirectionally. The structure and control system are critical for the soundness, efficiency and performance of the PCS. This paper summarizes the regularly utilized topology structures, and analyzes their disparities and characters. At that point the control procedure is introduced and summarized.

With the quick improvement of worldwide economy, the worldwide power utilization floods which offers ascend to the genuine power supply lack. Renewable energy sources, for example, wind turbine generators and photovoltaics gives another approach to determine the issue. Nonetheless, the conveyed power, for example, photovoltaic power and wind power are discontinuous and produce fluctuating active power. Interconnecting these discontinuous sources to the utility lattice at a large scale may influence the voltage and recurrence control of the framework, and may prompt extreme power quality issues. Therefore, Energy storage framework is significant for the smaller scale network, it can store the abundance power from the lattice when the power supply is more noteworthy than the power utilization. Then again, it discharges the lack of power to the framework when the age framework creates a smaller power. The energy storage framework acquires a huge improvement power quality, security and dependability to the network. Therefor, the energy storage framework is increasingly more broadly utilized in conveyed age framework and small scale lattice. 


\section{LITERATURE SURVEY}

O. Kwon et al., [1] This examination proposes a bidirectional lattice associated single-power-conversion converter with low-input battery voltage. The proposed bidirectional converter comprises of a bidirectional dc-dc converter and an unfurling bridge, and the power conversion stage just compares to a bidirectional dc-dc converter. The bidirectional dc-dc converter can perform bidirectional power conversion between the low input battery voltage and a redressed sine wave because of its progression up/down voltage guideline functions. The unfurling bridge unfurls the corrected sine wave into the framework voltage and gives a present way to the matrix. The investigation likewise proposes a control calculation to manage the framework current through a solitary power-preparing stage. The control calculation is involved a feed-forward ostensible voltage compensator and a dull control conspire. The feed-forward ostensible voltage compensator presets the working point to help the weight of the framework current control, and the redundant controller gives exact control of the matrix current. Consequently, the proposed bidirectional matrix associated single-power-conversion converter brings about high power quality and high efficiency.

N. Vamanan et al., [2] Dual-correlation one-cycle control for the bidirectional power stream in single-stage matrix associated converters is proposed in this work. Points of interest of dual-correlation one-cycle control when contrasted with ordinary one-cycle control is that it doesn't give any consistent state dc counterbalance, no light-load precariousness, and actualizes unipolar pulsewidth tweak without detecting the lattice voltage. Expansion of an imaginary current term, which is produced from the gating signal of one of the active gadgets, utilizing a bandpass channel, empowers the bidirectional power stream. The quality factor of the bandpass channel is appeared to affect the all out consonant twisting in current, principal relocation point, and consistent state dc counterbalance. The ideal estimation of a quality factor, acquired with help of recreations, gives an unrivaled performance. The current drawn or infused into the framework supposedly lags the network voltage. The explanation behind a nonunity uprooting power factor is analyzed and a pay to accomplish a solidarity dislodging power factor is likewise proposed in this work. Point by point reenactment and test studies are completed to approve the proposed control and the high performance that can be acquired.

M. Mellincovsky et al., [3] In this work, an offbeat strategy for dc connection mass capacitance active decrease without swell increment in mains-associated power conversion systems is proposed. Despite the fact that the embraced power hardware (a bidirectional dc-dc converter, ended by an a lot smaller capacitance) is practically equivalent to arrangements proposed forward-thinking, the idea of activity is very extraordinary. As opposed to controlling the current, streaming into the dc connect (i.e., working as a current controlled current sink, comparably to an active power channel), proposed arrangement directs the swell by controlling the dc interface voltage (i.e., working as a voltage controlled current sink) along these lines letting the matrix interfacing converter OFF the undertaking. This permits enlarging of the dc connect voltage circle bandwidth and, subsequently, lessening the swell for a similar capacitance utilized or decreasing the capacitance while keeping up a similar swell without exchanging off the power factor. So as to approve the proposed technique tentatively, it is effectively connected to a solitary stage off-the-rack power factor adjustment pre-converter.

Y. Jeong et al., [4] This work introduces a high-efficiency bidirectional network tied converter utilizing single power conversion with high-quality lattice present and a control framework for it. The proposed converter is made out of a bidirectional flyback dc-dc converter and an unfurling bridge circuit. By modifying the PWM signal of the flyback, the proposed converter performs bidirectional power conversion between the framework and energy storage gadget in just one stage. The control framework comprises of a feed-forward controller, a direct criticism controller with a low-pass channel, and a redundant controller. The improvement of the proposed control framework thinks about the intrinsic unique attributes of the converter, in this way defeating the requirements on planning criticism control increases starting in right-half-plane zero and LC channel elements. Therefore, the control framework guarantees wanted reference following and unsettling influence dismissal performances while fulfilling strength prerequisites. All in all, the proposed converter can accomplish high conversion efficiency through a solitary power conversion, and its control framework makes the usage of the single power conversion in the proposed converter possible. The hypothetical examination for the proposed converter and its control framework is portrayed.

S. Lee et al., [5] This work introduces a high-efficiency disconnected air conditioning dc converter topology. The proposed converter comprises of a full-bridge diode rectifier, a disengaged thunderous dc-dc converter, and just a single controller. The proposed converter gives the delicate changing method to all segments working at high recurrence, taking into consideration an improvement in power thickness without an expense of power-conversion efficiency. Moreover, by utilizing a novel control calculation that controls both power factor and yield power, the converter performs air conditioning dc power conversion in just a solitary power-handling step. These attributes empower the proposed converter to give high efficiency, high power thickness, and a high power factor. A 2 $\mathrm{kW}$ prototype was executed, and its performance and legitimacy were assessed dependent on trial outcomes.

K. Lo et al., [6] The goal of this work is to propose a bidirectional single-stage network associated inverter (BSGinverter) for the battery energy storage framework. The 
proposed BSG-inverter is made out of numerous bidirectional buck-boost type dc-dc converters (BBCs) and a dc-air conditioning unfolder. Favorable circumstances of the proposed BSG-inverter include: single-stage power conversion, low battery and dc-transport voltages, throbbing charging/releasing flows, and individual power control for every battery module. Therefore, the equalization, lifetime expansion, and limit adaptability of the battery energy storage framework can be accomplished. In view of the created conditions, the power stream of the battery framework can be controlled without the need of info current sensor. Likewise, with the interleaved activity between BBCs, the present swell of the yield inductor can be decreased as well. The PC reproductions and equipment exploratory outcomes are appeared to check the performance of the proposed BSG-inverter.

M. A. Hernandez Navas et al., [7] This work introduces a breeze power age framework (WPGS) with battery energy storage framework (BESS) in light of the Z-source inverter (ZSI) with straightforward boost control. Wind turbines utilizing the squirrel confine enlistment generator (SCIG) are broadly acknowledged because of their vigor, straightforwardness, light weight and minimal effort. The SCIG is associated with the power lattice through voltage source converters VSC, and the WPGS is reinforced by the BESS so as to keep framework power balance. The BESS has a battery bank, which is coordinated with the framework through a bidirectional DC-DC converter (buck-boost). In addition, the ZSI is an elective power conversion topology that can both (buck-boost) the information voltage utilizing aloof segments. The activity of ZSI is analyzed, and the active and reactive power decoupling strategy is proposed for a twofold shut circle control framework, which guarantees the security in voltage capacitor of ZSI.

M. Pahlevani et al., [8] This work shows another dctransport voltage control procedure for single-stage bidirectional air conditioning/dc converters. The proposed controller can essentially improve the transient reaction of the dc-transport voltage control circle and give a hearty and dependable shut circle control framework. In the proposed methodology, the dc estimation of the dc-transport voltage is definitely assessed through a particular versatile channel. The structure of the proposed channel gives a quick and powerful estimation for the dc estimation of the dc-transport voltage. Specifically, the proposed dc-extraction strategy can correctly assess the dc esteem in nearness of twofold recurrence swell mounted over the dc-transport voltage in single-stage air conditioning/dc converters. Reproduction and exploratory outcomes exhibit the unrivaled performance of the proposed shut circle control framework contrasted with the traditional ones.

W. Cha et al., [9] A solitary power-conversion Drove backdrop illumination driving framework with high power factor control is proposed. The proposed converter is made out of a full-bridge diode rectifier and a semi resounding flyback converter. The proposed converter gives a basic structure, a minimal effort, and high power factor of 0.988 by utilizing the novel control calculation without the PFC circuit. To accomplish great controllability, the novel control calculation is transformed by adding an ostensible worth foreordained to loosen up its control trouble. Definite examination and test results for a $90-\mathrm{W}$ prototype are talked about.

K. Kim et al., [10] This work shows a bidirectional single power-conversion dc-air conditioning converter with non corresponding active-clasp circuits. The proposed converter contains a bidirectional fly back converter and an unfurling bridge. So as to interface the lattice with a low-voltage energy storage through just single power-conversion, the bidirectional flyback converter transforms the low voltage straightforwardly into the collapsed framework voltage and directs the collapsed network current. The proposed converter receives non corresponding activity methodology for the active-brace circuits. By utilizing this methodology, the bidirectional fly back converter maintains a strategic distance from the voltage spike as well as minimizes the power misfortunes by the flowing energy. In this way, with single power-conversion and non corresponding active-cinch circuits, the proposed converter acquires high power efficiency. To encourage the bidirectional single power-conversion, a novel control calculation is created. With this control calculation, the proposed converter guarantees high network power quality and consistent mode progress.

Y. Cho et al., [11] This work proposes a high-efficiency bidirectional dual-active-bridge (Touch) inverter utilizing a novel hybrid tweak for a stand-alone power producing framework with a low input voltage. The proposed Touch inverter comprises of a Spot dc-dc converter and a synchronous rectifier (SR) for unfurling. The Touch dc-dc converter transforms the low dc voltage into an amended sine wave that throbs double the matrix recurrence. The amended sine wave unfurls into the framework voltage by SR. The proposed hybrid tweak joins a stage move control and a variable recurrence control. The variable recurrence control changes over the nonlinear capacity of the stage move point into a direct capacity and controls the yield power. This prompts a straightforward shut circle control for the sinusoidal current waveform, a low symphonious contortion, and a high-voltage conversion proportion without an expansion of the transformer turn proportion. 
Table 1: Summery of Literature Survey

\begin{tabular}{|c|c|c|c|c|}
\hline $\begin{array}{l}\text { Sr } \\
\text { No. }\end{array}$ & $\begin{array}{l}\text { Author } \\
\text { Name }\end{array}$ & $\begin{array}{l}\text { Publish } \\
\text { Detail }\end{array}$ & Proposed Work & Outcome \\
\hline 1 & $\begin{array}{l}\text { O. } \\
\text { Kwon }\end{array}$ & $\begin{array}{l}\text { IEEE } \\
\text { April } \\
2018\end{array}$ & $\begin{array}{l}\text { bidirectional } \\
\text { grid-connected } \\
\text { single-power- } \\
\text { conversion } \\
\text { converter }\end{array}$ & $\begin{array}{l}250-\mathrm{W} \\
\text { prototype } \\
\text { module are } \\
\text { conducted to } \\
\text { evaluate the } \\
\text { performance }\end{array}$ \\
\hline 2 & Y. Jeong & $\begin{array}{l}\text { IEEE } \\
\text { Nov } \\
2017\end{array}$ & $\begin{array}{l}\text { presents a high- } \\
\text { efficiency } \\
\text { bidirectional } \\
\text { grid-tied } \\
\text { converter }\end{array}$ & $\begin{array}{l}250 \quad \mathrm{~W} \\
\text { prototype are } \\
\text { represented to } \\
\text { confirm the } \\
\text { validity }\end{array}$ \\
\hline 3 & $\begin{array}{l}\text { M. A. A. } \\
\text { Hernand } \\
\text { ez }\end{array}$ & $\begin{array}{l}\text { IEEE } \\
\text { Sep } \\
2016\end{array}$ & $\begin{array}{l}\text { Presents a wind } \\
\text { power } \\
\text { generation } \\
\text { system }\end{array}$ & $\begin{array}{l}\text { high } \\
\text { performance, } \\
\text { minimal } \\
\text { component } \\
\text { count, } \\
\text { increased } \\
\text { efficiency }\end{array}$ \\
\hline 4 & $\begin{array}{l}\text { M. } \\
\text { Pahleva } \\
\text { ni }\end{array}$ & $\begin{array}{l}\text { IEEE } \\
\text { Aug } \\
2015\end{array}$ & $\begin{array}{ll}\text { New } & \text { dc-bus } \\
\text { voltage } & \text { control } \\
\text { technique }\end{array}$ & $\begin{array}{l}\text { superior } \\
\text { performance } \\
\text { of the } \\
\text { proposed } \\
\text { closed-loop } \\
\text { control } \\
\text { system }\end{array}$ \\
\hline 5 & W. Cha & $\begin{array}{l}\text { IEEE } \\
\text { May } \\
2014\end{array}$ & $\begin{array}{l}\text { single power- } \\
\text { conversion LED } \\
\text { backlight } \\
\text { driving system }\end{array}$ & $\begin{array}{l}90-\mathrm{W} \\
\text { prototype are } \\
\text { discussed }\end{array}$ \\
\hline
\end{tabular}

\section{VARIOUS POWER CONVERSION CONVERTERS}

\section{A. Topologies and Control Strategies of PCS}

The storage facility in this paper is referred to storage battery units. PCS is a power electronic converter in nature used to regulate the power transfer between the storage facility and micro-grid. Figure below show the structure of the whole energy storage system.

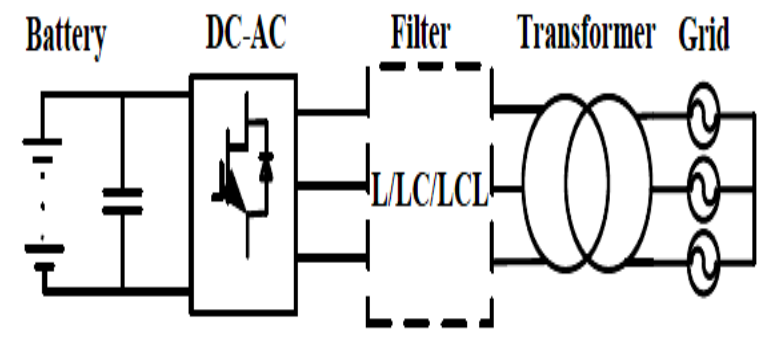

Figure 2: Topology of single-stage power conversion system
Structure of energy storage power conversion framework PCS has numerous topological structures, the generally utilized structures, for example, single-stage PCS, two-stage PCS and cascaded PCS will be introduced.

\section{B. Single-stage PCS}

Figure demonstrates the single-stage PCS topology. From the figure we can reason that the PCS is basically a bidirectional dc-air conditioning converter. This converter can not just ingest unnecessary energy from the lattice and store the power in battery units, yet in addition discharge energy put away in the battery banks to the network and convert the dc voltage to air conditioning voltage associated with the matrix so as to keep the equalization of the framework. Besides, a channel could be introduced in the yield side of the battery unit to sift through the sounds and relieve the swell in the flows infused into the network. Battery DC-Air conditioning Channel Transformer Lattice L/LC/LCL Fig. Topology of single-stage power conversion framework The conspicuous points of interest of single stage PCS are the straightforward circuit structure, moderately basic control technique, and less switch amount which means less misfortunes. Anyway, the disservice is likewise self-evident, the activity dc voltage of the battery units is restricted; absence of adaptability of framework limit setup and current-leveling capacity of the battery units is poor, which successfully influence the battery lifetime. For the single-stage PCS, there two goes for the control technique. One is guaranteeing the parity of the active power in the lattice, the other one is keeping up the voltage and recurrence soundness of the matrix when erratic occasions happen and supporting the basic burden associated with the network. As of now, the normally utilized control strategies incorporate PQ control, V/f control and steady current control.

\section{Two-stage PCS}

Figure demonstrates the two-stage PCS topology. This PCS comprise of two converters: bidirectional dc-air conditioning converter and bidirectional dc-dc converter. The dc-dc converter is basically utilized for boosting or bucking the dc voltage and give a steady dc voltage. Dc-air conditioning converter work in the condition of correction mode when the battery units discharge power and convert the air conditioner voltage of the lattice to dc voltage. This dc voltage will be managed by the dc-dc converter and put away in the battery. At the point when the battery discharge energy, the yield dc voltage of the battery units is boosted by dc-dc converter and give appropriate information dc voltage to dc-air conditioning converter. Finally yield a fitting air conditioning voltage required by utility framework. L/LC/LCL Battery DC-Air conditioning Channel Transformer Matrix .

In the down to earth application, bidirectional dc-dc converter is categorized by disengaged dc-dc converter and nondetached converter. The distinction between the two sorts of 
converters is whether there is a high recurrence disconnection transformer. presented in detail the customary non-confined dc-dc converters, for example, bidirectional dc-dc converter, bidirectional Boost/Buck converters, bidirectional Cuk converters and bidirectional Sepic converters. They all advanced by fundamental unidirectional converter. introduced a novel converter consolidated interleaving innovation with the non-disengaged dc-dc converters in order to bring down inductance planning necessities and decrease the voltage and current weight on the switches. The confined converter principally incorporate flyback-typed converter, forward-typed converter push-pull-typed converter and bridge-typed converter.

The upsides of Two-stage PCS are: the working voltage rang of the battery unit is moderately higher than the single-stage PCS; the charging current swell is small and the symphonious part is generally basic; the second request consonant segment of the charging current in the single-stage or three-stage uneven framework can be restrained by dc-dc converter; this structure 263 has a high degree adaptability in cells portion of battery units. In any case, the downsides of this structure comprise in the large number of switches which brings more misfortunes and diminish the efficiency of PCS.

For the two-stage PCS, dc-dc converter is utilized to control charging/releasing current for the battery units, in this manner a current-circle is embraced to accomplish a steady charging/releasing current. While the dc-air conditioning converter is planned to continue the middle dc voltage steadiness and accomplish the objective of the solidarity power factor activity. A twofold circle control plan comprising of an external voltage circle and an internal current circle is regularly received. The internal current circle is to control the current infused to framework as indicated by the command signal in order to accomplishing solidarity power factor activity. While the external voltage circle is intended to keep up the dc-interface voltage and produce command current signal to the internal circle.

Symphonious voltage of the reactor could be distinguished rapidly by methods for a quick consonant voltage discovery calculation, and comparing consonant voltage is created to repay the impact of the matrix voltage consonant by this dull control to diminish the network current complete consonant mutilation. Anyway this strategy can not realize zero static blunder of current following. To tackle this issue Reference [7] gave a dreary plan voltage feed-forward consolidated the PI control with the PR control. PI realized the zero static mistake following of the network associated current, while PR realized the viable concealment of the specific sounds, in order to improved the nature of the framework associated current.

\section{Cascade multilevel PCS}

$\mathrm{H}$-bridge converter is progressively generally utilized in viable application. To decrease the batteries ostensible voltage, the quantity of arrangement associated storage cells can be circulated in various converter cells utilizing the cascaded $\mathrm{H}$ bridge converter. This cascaded H-bridge structure enables direct association with a medium-voltage framework with less voltage/current music without get any expansion voltage rating to individual exchanging devices[8]. In addition, as the structure of every converter cells are same, that will encourages the modularization planning and pressing. Topology of the cascaded multilevel PCS. B C BMS Battery units Battery units Battery units Battery units Framework Fig.6 Topology of Cascaded H-bridge Converter Cascaded Hbridge converter has numerous points of interest. Initially, multilevel yield could redesign the present quality infused to the matrix. Furthermore, cascaded structure diminish the voltage in each 264 converter cells and carry a decrease to switch misfortunes, and have a proportionate exchanging recurrence under the principal exchanging recurrence working condition. In addition, it likewise has a simple and adaptable augmentation capacity in light of the secluded pressing of the converter. As of late, there are not many inquires about on control technique of cascaded H-bridge PCS. Power conversion is changing over electric energy starting with one form then onto the next, for example, changing over among air conditioning and DC; or changing the voltage or recurrence; or a mix of these. A power converter is an electrical or electromechanical gadget for changing over electrical energy. This could be as basic as a transformer to change the voltage of air conditioning power, yet additionally incorporates unmistakably increasingly complex systems. The term can likewise allude to a class of electrical hardware that is utilized to change over one recurrence of rotating flow into another recurrence.

Power electronic innovation manages preparing and controlling the progression of electrical energy so as to supply voltages and flows in a form that ideally appropriate for end client's prerequisites.

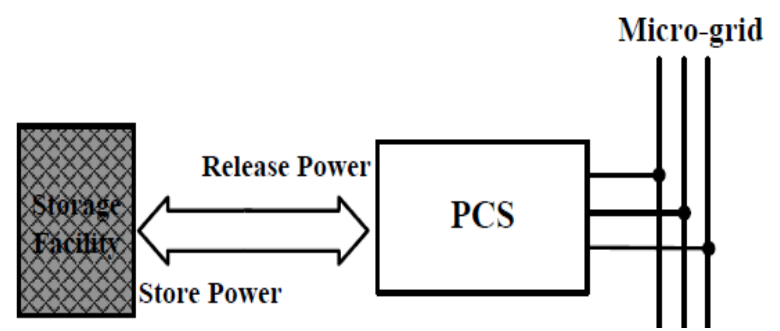

Figure 3: Structure of energy storage power conversion system

The block diagram of a power electronic converter is appeared in figure above. It comprise of an electrical energy source, power electronic circuit, a control circuit and an electric burden. This converter transforms one form of electrical energy to other form of electrical energy.

The power electronic circuit comprises of both power part and control part. Power part moves the energy from source to load 
and it comprises of power electronic switches (SCR or TRIAC), transformers, electric gag, capacitors, wires and now and then resistors.

The control circuit or square manages the components in the power some portion of the converter. This square is worked with an unpredictable low power electronic circuit that comprises of either simple or advanced circuit assembly.Power electronic converters perform different fundamental power conversion functions. This converter is a solitary power conversion stage that can perform any of the functions in air conditioning and DC power conversion systems.

Depending on the type of function performed, power electronic converters are categorized into following types.

- $\quad \mathrm{AC}$ to $\mathrm{DC}=$ Rectifier: It converts $\mathrm{AC}$ to unipolar (DC) current

- $\quad \mathrm{DC}$ to $\mathrm{AC}=$ Inverter: It converts $\mathrm{DC}$ to $\mathrm{AC}$ of desired frequency and voltage

- $\quad$ DC to DC = Chopper: It converts constant to variable DC or variable $\mathrm{DC}$ to constant $\mathrm{DC}$

- $\mathrm{AC}$ to $\mathrm{AC}=$ Cycloconverter, Matrix converter: It converts $\mathrm{AC}$ of desired frequency and/or desired voltage magnitude from a line AC supply.

These types of power electronic converters may be found in a wide variety of applications such as switch mode power supplies (SMPS), electrical machine control, energy storage systems, lighting drives, active power filters, power generation and distribution, renewable energy conversion, flexible AC transmission and embedded technology.

\section{CONCLUSION}

With the continuous progress of batter technology and power gadgets innovation, the structure of the PCS will be reexamined and improved. In the current functional application, single-stage PCS will be ordinarily and widely utilized in the small and medium power application thinking about the efficiency and cost. While in high power application, the particular cascaded H-bridge PCS is the most reasonable decision. The new structure creates towards a heading of less misfortunes, higher dependability, higher effective expense and higher level of particularity. Additionally, as the control procedure is winding up increasingly full grown, PCS could deftly embrace distinctive control strategies as indicated by various working modes or control targets.

\section{REFERENCE}

[1]. O. Kwon, J. Kim, J. Kwon and B. Kwon, "Bidirectional GridConnected Single-Power-Conversion Converter With LowInput Battery Voltage," in IEEE Transactions on Industrial Electronics, vol. 65, no. 4, pp. 3136-3144, April 2018.

[2]. N. Vamanan and V. John, "Dual-Comparison One-Cycle Control for Single-Phase Bidirectional Power Converters," in IEEE Transactions on Industry Applications, vol. 54, no. 5, pp. 4621-4631, Sept.-Oct. 2018.
[3]. M. Mellincovsky, V. Yuhimenko, Q. Zhong, M. Mordechai Peretz and A. Kuperman, "Active DC Link Capacitance Reduction in Grid-Connected Power Conversion Systems by Direct Voltage Regulation," in IEEE Access, vol. 6, pp. 1816318173, 2018.

[4]. Y. Jeong, S. Lee, S. Jeong, J. Kwon and B. Kwon, "HighEfficiency Bidirectional Grid-Tied Converter Using Single Power Conversion With High-Quality Grid Current," in IEEE Transactions on Industrial Electronics, vol. 64, no. 11, pp. 8504-8513, Nov. 2017.

[5]. S. Lee, W. Cha and B. Kwon, "High-Efficiency Soft-Switching AC-DC Converter With Single-Power-Conversion Method," in IEEE Transactions on Industrial Electronics, vol. 64, no. 6, pp. 4483-4490, June 2017

[6]. M. A. Hernandez Navas, F. Lozada G., J. L. Azcue Puma, J. A. Torrico A. and A. J. Sguarezi Filho, "Battery Energy Storage System Applied to Wind Power System Based On Z-Source Inverter Connected to Grid," in IEEE Latin America Transactions, vol. 14, no. 9, pp. 4035-4042, Sept. 2016.

[7]. J. Pereda and T. C. Green, "Direct Modular Multilevel Converter With Six Branches for Flexible Distribution Networks," in IEEE Transactions on Power Delivery, vol. 31, no. 4, pp. 1728-1737, Aug. 2016.

[8]. M. Pahlevani and P. Jain, "A Fast DC-Bus Voltage Controller for Bidirectional Single-Phase AC/DC Converters," in IEEE Transactions on Power Electronics, vol. 30, no. 8, pp. 45364547, Aug. 2015.

[9]. W. Cha, Y. Cho, J. Kwon and B. Kwon, "Single PowerConversion LED Backlight Driving System With High Power Factor Control," in Journal of Display Technology, vol. 10, no. 5, pp. 407-413, May 2014.

[10]. Y. Cho, J. Kwon and B. Kwon, "Single Power-Conversion AC-DC Converter With High Power Factor and High Efficiency," in IEEE Transactions on Power Electronics, vol. 29, no. 9, pp. 4797-4806, Sept. 2014

[11].B. Su, H. Wen, J. Zhang and Z. Lu, "A soft-switching postregulator for multi-outputs dual forward DC/DC converter with tight output voltage regulation," in IET Power Electronics, vol. 6, no. 6, pp. 1069-1077, July 2013.

[12].X. Lu, J. Guerrero, R. Teodorescu, T. Kerekes, K. Sun and L. Huang, "Control of parallel-connected bidirectional AC-DC converters in stationary frame for microgrid application," 2011 IEEE Energy Conversion Congress and Exposition, Phoenix, AZ, 2011, pp. 4153-4160. 